\title{
The Mulligan Concept in the Treatment of Anterior Knee Pain
}

Karla S. Judge, DAT, LAT, ATC ${ }^{\text {; }}$ Alan Nasypany, Ed.D., LAT, ATC²; Russell T. Baker, PhD, LAT, ATC²; and James May, DAT, LAT, ATC2

'Idaho State University, Pocatello ID; 2 University of Idaho, Moscow, ID

\section{ABSTRACT}

The purpose of the disablement model case study was to describe the case of a collegiate basketball player suffering from anterior knee pain (AKP). The patient had been experiencing AKP while participating in pre-season basketball related activities (playing, weight lifting, and conditioning) for approximately six weeks. As the intensity increased, the pain became intolerable. Previously, the patient had missed a significant amount of off-season workouts due to surgery for an upper extremity injury sustained during the competitive season. The patient reported tenderness at the inferior pole of the patella, and at the tibial tuberosity. There was no joint line tenderness, swelling, tissue temperature change, crepitus, or joint locking identified during the initial assessment. Manual muscle testing revealed decreased strength and pain at the inferior pole of the patella and the tibial tuberosity with the long sitting straight leg raise, as well as seated knee extension. Patient reported outcome measures were used to establish a baseline of pain and function. The Disability of the Physically Active Scale, the Numeric Pain Rating Scale, and the Patient Specific Functional Scale were used to identify patient-centered, as well as clinician-centered changes produced by the treatment intervention. Recording of outcome measures took place at the initial assessment, after the initial treatment intervention, two days after the initial intervention, and one and two weeks after the initial intervention. Outcome measures reflected a positive result for the decrease of pain with basketball activities, as well as activities of daily living. Evidence supports the use of mobilizations to treat tendinopathies, joint positional faults, and neuromuscular motor control. While evaluating and treating patients with the Mulligan Concept $M W M$, the clinician receives immediate feedback regarding the efficacy and potential success of the intervention strategy. The purpose of this case study was to describe the application of the Mulligan MWM philosophy and tibial internal rotation (TIR) technique while treating a patient complaining of AKP in an intercollegiate athletic training clinic.

\section{Key Phrases}

Manual techniques, patient-reported outcomes, mulligan concept, sub-therapeutic dose

\section{Correspondence}

Dr. Karla Judge, Idaho State University, 921 South $8^{\text {th }}$ Ave, Pocatello, ID, 83209

Email: judgkarl@isu.edu

\section{Full Citation}

Judge KS, Nasypany A, Baker RT, May J. The Mulligan Concept in the Treatment of Anterior Knee Pain. Clin Pract Athl Train. 2019;2(3):48-57. https://doi.org/10.31622/2019/0003.5.

Submitted: November 29, 2018 Accepted: October 18, 2019

\section{INTRODUCTION}

\section{Anterior knee pain (AKP) is a common complaint}

in athletics. ${ }^{1}$ Multiple conditions can produce pain at the anterior knee and an accurate assessment is necessary to direct proper treatment. Patellar tendinopathy, patellofemoral pain syndrome, quadriceps tendinopathy, chondromalacia, synovial plica, bursa and meniscal lesions can all present as AKP.' Poor motor control of the hip, pelvis and knee has also been identified as a possible cause of AKP.1-7 Ultimately, loss of efficient motor control of hip abductors, adductors, extensors and knee flexors may lead to poor joint kinematics, resulting in AKP. 2-7,12,14,15 The Mulligan Concept (MC) was developed on a positional fault theory, which is based on the belief that minor malalignment of joint surfaces may be present, resulting in swelling, stiffness, and pain. ${ }^{12-18}$ The Mobilization with Movement (MWM) may address this minor joint malalignment, as well as help create a more ideal neurophysiological environment for improved motor control and pain-free movement strategies. ${ }^{15}$ A MWM has been defined as a "sustained passive accessory force/glide to a joint while the patient actively performs a task that was previously painful". ${ }^{15}$ The force is applied parallel to the treatment plane and should be a light, gentle force, just enough to improve motion and reduce pain. During assessment, the clinician will identify the direction of the force applied to the joint line in order to produce a positive outcome. 
Two acronyms help guide and define proper application of the MC MWM.12-18 First, identified in Table 1 is the PILL acronym. Pain free, Immediate, and Long Lasting identifies the desired result of the mobilization technique. The most important part of the PILL acronym is the pain free aspect of the mobilization. If pain is not eliminated, then small changes in direction (addition of a minor rotation) or force (increase or decrease) can be made to improve symptoms. An immediate improvement of pain-free range of motion (ROM) is expected at the time of the mobilization. If the results are not long lasting, changes should be made regarding the number of sets or repetitions used during the mobilization. ${ }^{15}$

Table 1. The Mulligan Concept PILL Acronym for Performing a Mobilization with Movement $12-18,21$

P Pain free: the immobilization should be
pain free
I Immediate: reduction of pain and increase
of functional activity
LL Long Lasting: the result of the mobilization
should have a long lasting effect in
reduction of pain

Second, Table 2 identifies the CROCKS acronym, "Contraindications, Repetitions, Overpressure, communication, Knowledge, Sustain/sense/skills/success", which guides the technique and expectations of the mobilization for both the clinician and patient. ${ }^{12-18}$ The clinician should possess knowledge of the indications and contraindications of joint mobilization techniques, in general, as well as specific knowledge regarding the MWM technique to ensure a safe intervention. ${ }^{12-18}$ Joint health and any underlying pathology also need to be clearly understood to avoid exacerbating any existing condition, such as fractures, rheumatoid arthritis, or poor skin integrity. Sets and repetitions may vary depending on treatment area, length of dysfunction, and treatment calendar. ${ }^{12-18}$ For example, spinal manipulations are treated with fewer repetitions than peripheral joints or in patients presenting in severe pain.12-18 One set of three repetitions would be used for the first intervention for a spinal mobilization, while a

Copyright ( $)$ by Indiana State University All rights reserved. ISSN Online 2577-8188 peripheral joint may be treated with three sets of six to ten repetitions. ${ }^{12-18}$ Overpressure added to the end of the active mobilization is believed to aid in providing optimal recovery. ${ }^{12-18}$ Communication between the clinician and the patient is imperative. The clinician must explain the process of the mobilization, and the patient must be able to communicate if any pain is experienced during the mobilization. ${ }^{12-18}$ Finally, a clinician possessing proper skills will sustain the mobilization through the entire ROM in order to have a successful treatment intervention. ${ }^{12-18}$

Table 2: Mulligan Concept "CROCKS" acronym for guidelines and expectations of a mobilizations with movement. ${ }^{12-18,21}$

C Contraindications: do any conditions exist that would limit the use of joint mobilization

$\mathbf{R}$ Repetitions: three sets of ten repetitions are used for treating the extremity joints

- Overpressure: passive overpressure is applied by either the patient or the clinician at the end range of movement

C Communication: between the clinician and the patient about the treatment, techniques and expectations before the intervention begins. During the intervention the patient should report any pain.

K Knowledge: the clinician should possess knowledge of joint planes of motion being treated

S Sustain, sense, skills, and success: using common sense and clinical skills, the mobilization should be sustained throughout the movement in order to attain success.

A common mobilization used for AKP is the tibial internal rotation (TIR) MWM. The TIR MWM is often the first technique clinicians will utilize to treat reported pain and/or dysfunction at the knee. ${ }^{12-15,17,18}$ The TIR MWM technique includes a clinician-directed rotational mobilization force added to the patient-directed flexion and extension movement across the treatment plane (the tibial plateau).12-15 The TIR MWM can be reinforced with a tape application that may be worn until the patient's return to the clinic in 24-48 hours (standard precautions for tape application must be considered). $12,14,15$ The desired effect of the tape is to sustain the mobilization effect and 
apply continual neurological input for more ideal motor control.15 The mobilization and tape application are intended to enable pain free movement and motor control by addressing the malalignment of tibial external rotation, decreasing medial hamstring inhibition, and decreasing pain. 15 Short term re-training of motor control can have a prolonged positive effect on pain and therefore is important to facilitate pain free movements, while treating painful and restricted joints.7

The MC MWM can also be incorporated into the patient assessment as well as an intervention tool.15 Along with observation, palpation, functional and special tests, the application of a single set of six repetitions ("sub-therapeutic dose") of the MWM can provide valuable information. A decrease of pain during the subtherapeutic dose of MWM can indicate to the clinician that the MWM could produce a successful outcome.15 A decrease of pain with the knee flexion movement will indicate the MWM is clinically indicated to treat the AKP and assist in re-establishing joint alignment and motor control.

\section{PATIENT INFORMATION}

The patient was a 19-year old male intercollegiate basketball player. He was a 6'1", point guard weighing 205 pounds. During the past off-season, this patient had undergone surgery for an upper extremity injury which limited his ability to participate in summer conditioning activities. $\mathrm{He}$ reported to the athletic training clinic with a primary complaint of intermittent AKP pain for approximately six weeks. Low level knee pain began shortly after the start of fall semester workouts. Initially, the patient had been able to participate in basketball activity, weight lifting, and conditioning. As the intensity of conditioning increased, the patient became unable to participate in basketball-related activities. The patient had been self-treating with patellar strapping and ice, which is a treatment he used previously when he experienced AKP.

Copyright ( $)$ by Indiana State University 50

All rights reserved. ISSN Online 2577-8188

\section{DIFFERENTIAL DIAGNOSIS AND EVALUATION}

The patient presented with point tenderness to palpation at the tibial tuberosity and the inferior pole of the patella with his knee resting in extension. The patient denied complaints of tenderness, locking, or popping of the joint line. The patient also denied any previous OsgoodSchlatter or Sinding-Larson-Johansson diagnosis by a medical professional. No crepitus was present. There was no point tenderness or temperature changes along the length of the patellar tendon. All passive and active ROM were within normal limits (WNL) at the hip, knee, and ankle bilaterally. Trunk flexion, extension, and rotation motions were WNL and pain free. Bilateral lower extremity manual muscle testing resulted in 3/5 with pain reported at the inferior pole of the patella during the long sitting straight leg raise and seated knee extension, while all other muscle tests resulted in 5/5. The patient presented with normal patellar alignment, and both Clarke's sign for patellofemoral irritation and the patellar apprehension tests were negative. At the completion of the assessment, the differential diagnosis included: patellar tendinopathy, dysfunctional patellar tracking, Hoffa's fat pad irritation.

\section{BODY STRUCTURE AND FUNCTION}

The long sitting straight leg test was used as the client specific impairment measure (CSIM). ${ }^{15}$ The CSIM is a baseline test that is easily and safely reproducible in the clinic, prior to any functional or dynamic movement based testing. The CSIM is used to assess the treatment effects regarding pain or function. The test should be patientcentered and meaningful to the patient. ${ }^{15}$ The long sitting straight leg test was used for the CSIM for this patient due to the painful result of the manual muscle testing during the initial assessment.

After completion of the functional and special tests, the clinician included a "sub therapeutic dose" (1x6 repetitions) of the MC TIR MWM to

\footnotetext{
Clinical Practice in Athletic Training Volume 2 - Issue 3 - November 2019
} 
identify if the joint mobilization could produce a positive effect on the patient reported pain. ${ }^{15}$ Incorporating a sub-therapeutic dose of the mobilization into the assessment allows the clinician to determine if a MWM is clinically indicated. ${ }^{15}$ During the sub-therapeutic dose, the patient reported a pain-free MWM and immediate decrease in painful knee flexion. As the sub-therapeutic MWM dose matched the PILL response, the clinician determined the MC TIR $M W M$ was clinically indicated to treat the patient's AKP.

The patient had been self-treating his AKP over the preceding four days with no improvement of symptoms. He experienced pain at $110^{\circ}$ of knee flexion, as well as seated knee extension and while performing a straight leg raise. After the positive result of the sub therapeutic dose of TIR $M W M$, the clinician was encouraged to proceed with a full intervention before scheduling further diagnostic testing.

Prior to the examination, three patient-oriented outcome measures were administered to establish a baseline to measure the effect of patient care. First, the disability of the physically active scale

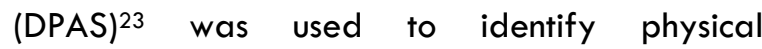
impairments, functional limitations, and quality of life changes that have taken place due to the injury. ${ }^{23}$ It has been designed to provide descriptive themes that are clinically meaningful to athletes. The DPAS has shown to be reliable, valid and responsive in the evaluation and monitoring of physically active patients. ${ }^{24}$ Second, the patient rated his pain on a 0-10 scale "least pain to most pain" using the numeric pain rating scale (NRS). ${ }^{25}$ The NRS has shown to be a sensitive and valid instrument in detecting changes in pain. ${ }^{25}$ Third, the patient completed the patient specific functional scale $(P S F S)^{26}$ to identify movements that are important to him in daily or sport activities (descending stairs, single leg landing, weight lifting, kneeling). The patient graded his ability to perform each activity on a scale of 0-10 "poor ability to best ability". The

Copyright (C) by Indiana State University All rights reserved. ISSN Online 2577-8188
PSFS has shown to have excellent test-retest reliability and is sensitive to changes. ${ }^{26}$ The treating clinician compared initial and follow-up scores at pre-determined intervals (initial, two days, one week, two weeks). The results at the initial and follow-up intervals are listed in Table 3.

Table 3: Initial Assessment and Follow-Up Scores of AKP

\begin{tabular}{lcccc}
\hline & Initial & $\begin{array}{c}2 \\
\text { days }\end{array}$ & $\begin{array}{c}1 \\
\text { week }\end{array}$ & $\begin{array}{c}2 \\
\text { weeks }\end{array}$ \\
\hline DPAS & 19 & 8 & 0 & 0 \\
NRS & 5 & 0 & 0 & 0 \\
PSFS: & & & & \\
$\begin{array}{l}\text { 1)descending } \\
\text { stairs } \\
\text { 2)single leg }\end{array}$ & 4 & 9 & 9 & 10 \\
$\begin{array}{l}\text { landing } \\
\text { 3)weight } \\
\text { lifting }\end{array}$ & 4 & 9 & 9 & 10 \\
$\begin{array}{l}\text { 4)kneeling } \\
\text { DPAS-Disability Of Physically Active Scale; }\end{array}$ \\
$\begin{array}{l}\text { NRS-Numeric Pain Rating Scale; PSFS-Patient } \\
\text { Specific Functional Scale }\end{array}$
\end{tabular}

Results of the outcome measures were used to assess if changes have met minimal clinically important difference (MCID) standards. ${ }^{27}$ An $M C I D$ is considered the minimum change that takes place as a result of the intervention that is important to both the patient and the clinician. ${ }^{27}$ To be considered MCIDs, changes include a pain decrease of six points for chronic pain (pain present for more than 6 weeks) or nine points for acute pain (pain present for less than 6 weeks) on the DPAS, a decrease of two points on the NRS and a three point change on the PSFS. ${ }^{23-27}$

\section{ACTIVITY AND PARTICIPATION}

The patient had been participating in pre-season individual workouts, weight lifting, conditioning, and playing unsupervised basketball for four weeks with AKP until the pain became unbearable the day prior to reporting for assessment. The patient did not feel the AKP was affecting his 
personal relationships or limiting his social activities.

\section{ENVIRONMENTAL AND PERSONAL FACTORS}

The patient was, however, very concerned about missing more team activities, as he had been unable to participate in any activities during the summer months. He had been the starting point guard and was anxious that he would lose his role on the team. His AKP was also affecting his ability to sit in class comfortably and to walk up and down stairs to his apartment.

\section{INTERVENTION}

To perform the MWM, the patient's left foot was placed on a non-rolling stool with the knee and hip flexed to $90^{\circ}$. A chair may be placed near the patient for balance if he/she feels uncomfortable standing on unaffected limb. Figure 1 illustrates the starting position for the MWM.

Prior to the mobilization, the patient reported $7 / 10$ pain at the tibial tuberosity with the knee flexed to $110^{\circ}$. To complete the MWM, the clinician placed one hand medially around the superior tibia close to the joint line without contacting the tender tibial tuberosity and the other hand grasped the lateral portion of the proximal tibiofibular joint. Figure 2 illustrates the starting hand position to perform the TIR MWM.

The clinician applied internal rotation of the tibia and maintained the rotation throughout the entire ROM as the patient moved through available pain-free knee flexion and returned to the starting position (Figure 3 ).

During the MWMs, the clinician communicated with the patient regarding any discomfort that may have occurred guided by the CROCKS acronym. The intervention continued with two more sets of the MWM, following the treatment recommendation of three sets of 10 repititions. ${ }^{11-}$ 19 After the completed treatment, the patient

Copyright (C) by Indiana State University All rights reserved. ISSN Online 2577-8188 reported 0/10 pain at both the inferior pole of the patella or tibial tuberosity. The CSIM, long sitting straight leg raise, was also reassessed with the patient reporting a NRS score of 0/10 (MCID for pain) and the MMT was assessed as 5/5. Pain scores and knee flexion ROM changes are described in Table 4.

Table 4: Pain Level and ROM Available Prior to, During and After The MWM was Performed

\begin{tabular}{lcc}
\hline $\begin{array}{l}\text { Test Intervals } \\
\text { Before MWM }\end{array}$ & NRS & $\begin{array}{c}\text { Knee Flexion } \\
\text { ROM }\end{array}$ \\
$\begin{array}{l}\text { After sub- } \\
\text { therapeutic dose } \\
\text { of MWM }\end{array}$ & 4 & $110^{\circ}$ \\
$\begin{array}{l}\text { After } 1^{\text {st }} \text { set of } \\
\text { MWM } \\
\text { After } 3^{\text {rd }} \text { set of } \\
\text { MWM }\end{array}$ & 4 & $120^{\circ}$ \\
\hline
\end{tabular}

NRS-Numeric Pain Rating Scale; ROM-Range of Motion

The MC guidelines recommend applying tape to reinforce the mobilization, assisting proprioceptive accommodations to the length and load of the new joint position created through the MWM intervention. ${ }^{12-15,17,18}$ The tape application is intended to mimic the MWM as the patient goes about their daily activities. While standing, the knee is placed in slight flexion $\left(10^{\circ}\right)$ and full internal tibial rotation. The clinician applies the tape by starting laterally at the proximal fibular head, matching the MWM direction and force, and crossing to the medial aspect of the tibia in a spiral fashion. The tape application continued superiorly, on the posterior knee to the lateral thigh. ${ }^{2-15,18}$ The patient reported the tape application resulted in the same joint position sensation as the hands-on mobilization. Figure 4 illustrates the completed tape application.

\section{OUTCOMES}

\section{BODY STRUCTURE AND FUNCTION}

Clinical Practice in Athletic Training Volume 2 - Issue 3 - November 2019 
The patient returned after the weekend (two days after the initial intervention) for a follow-up visit to assess the changes to the MWM and the PILL

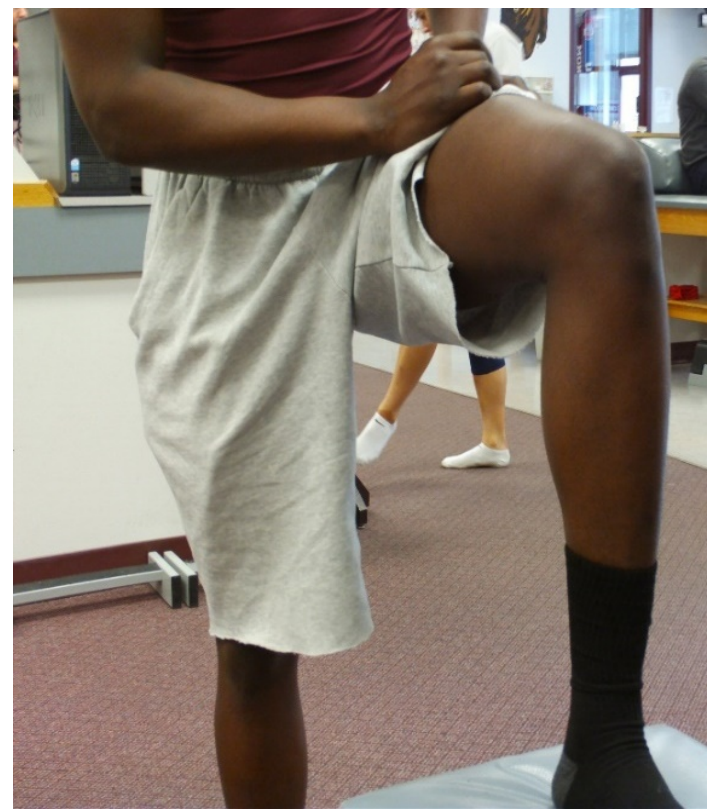

Figure 1: Starting Position for TIR MWM

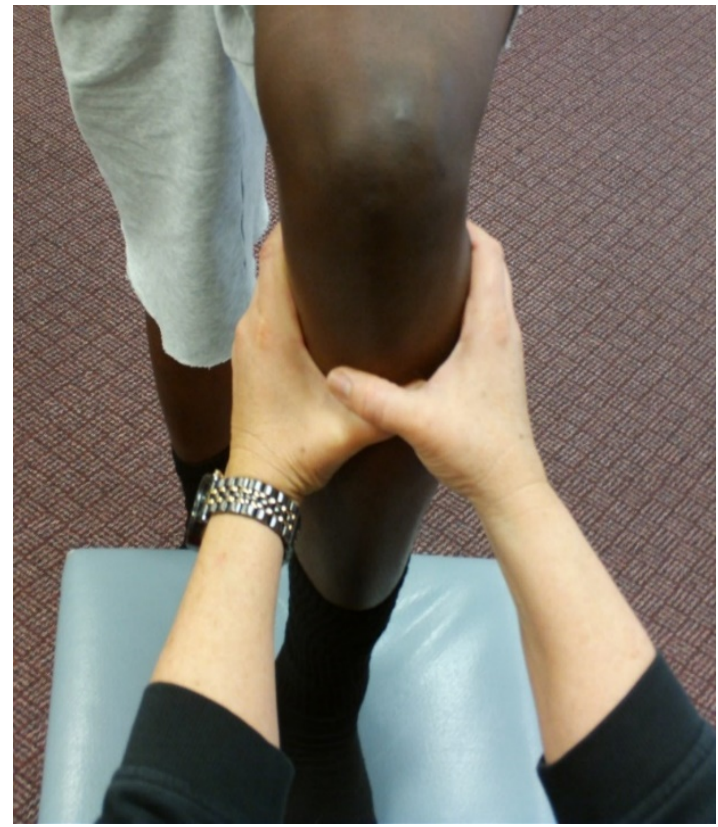

Figure 2: Clinician's Hand Placement to Perform TIR MWM.

Right hand is encompassing the head of the fibula while the left hand contacts the medial tibia. Both hands avoid contacting the tender tibial tuberosity.

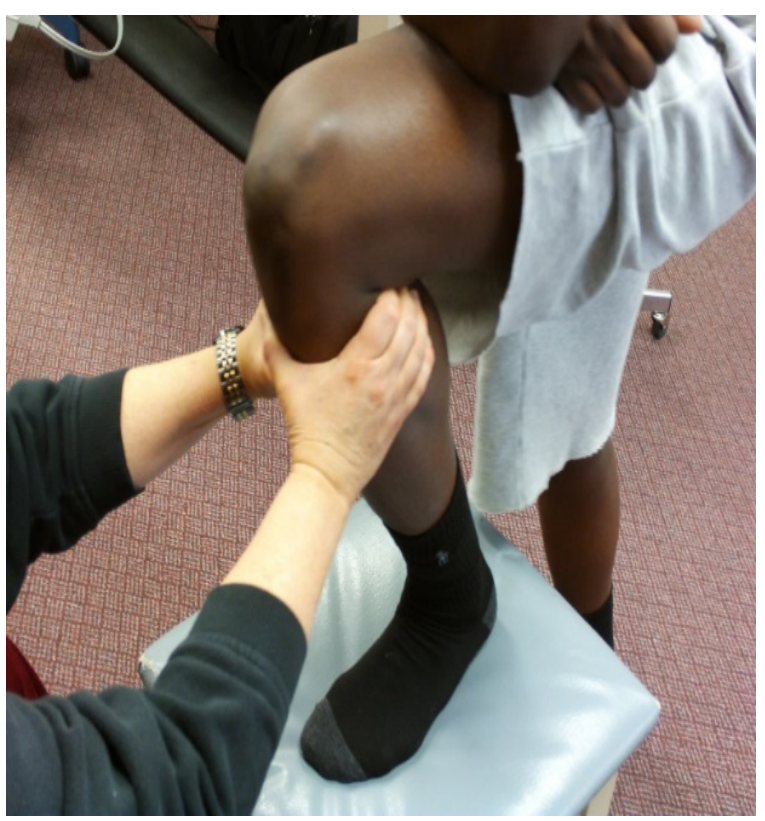

Figure 3: Maintaining Manual Contact Throughout the Mobilization

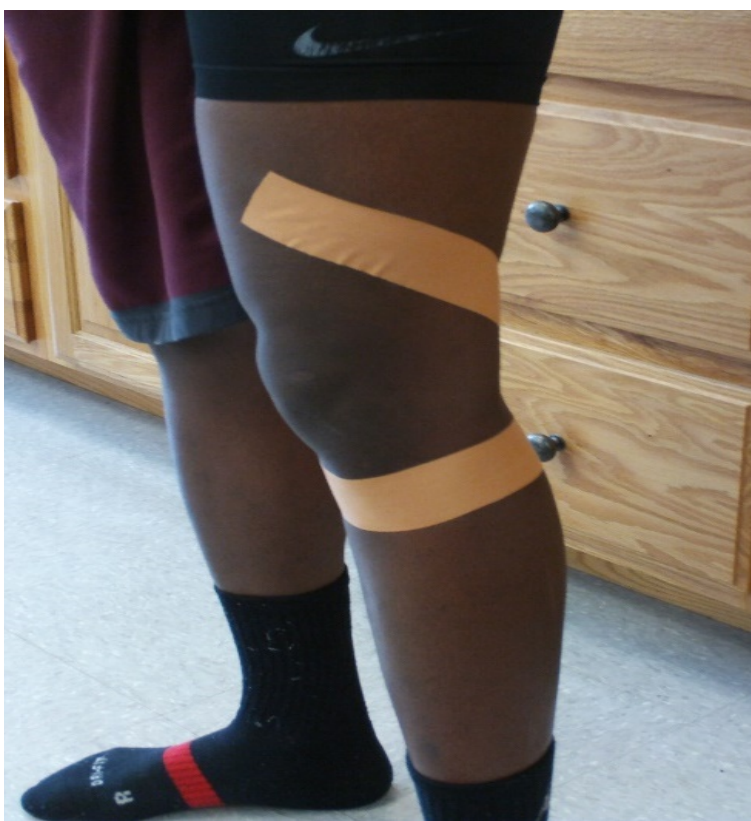

Figure 4: Tape Application Following TIR MWM. Small wrinkles of the tape may arise as the skin shifts under the adhered tape. 
response, as well as monitor any adverse effects the tape may have had on his skin. ${ }^{12-20}$ At the first follow-up, the patient reported $0 / 10$ pain during daily activity over the preceding two days, and reported a score of eight on the DPAS (MCID). The clinician repeated bilateral manual muscle testing resulting in $5 / 5$ for all motions, including seated knee extension, which had previously been recorded at $3 / 5$ with pain at the inferior pole of the patella. The clinician performed another intervention of $3 \times 10$ mobilizations followed by a new tape application and the patient was advised to return to the athletic training clinic for follow-up care as needed. To continue to collect patient centered outcomes, the patient was asked to return at one week intervals, unless there was a return of painful activity sooner. At the first one week interval, the patient reported $0 / 10$ tenderness at the inferior pole of the patella and at the tibial tuberosity. A TIR MWM was not performed at the one week interval due to the patient reporting pain-free activity. At the final outcome collection two weeks after the initial intervention, the patient remained pain-free. Both the patient-reported DPAS and NRS were recorded at $0 / 10$, while the PSFS activities all were recorded at 10/10. Due to the patient reported responses on the outcome measures, TIR MWM was not performed at the second week follow-up visit. The patient was discharged with the understanding he should return to the athletic training clinic if there was a return of either pain or dysfunction.

\section{ACTIVITY AND PARTICIPATION}

The patient had not participated in any physical activity for two days following the initial intervention. He reported pain-free activities of daily living, which included walking up and down stairs and sitting in class. At the follow up visit two days after the initial intervention, the clinician recommended modified return to basketball activity, suggesting he participate in individual workouts, weight lifting and half the volume of each running workout as pain permitted. The

Copyright (C) by Indiana State University All rights reserved. ISSN Online 2577-8188 patient determined that he would increase his activity as long as he was pain free and had returned to full basketball activities and reported $0 / 10$ pain with all activity.

\section{ENVIRONMENTAL AND PERSONAL FACTORS}

The patient was very anxious to return to activity due to his extended time away previously. His non-basketball painful activities (descending stairs and sitting in class) had decreased immediately and were completely eliminated within two days. While it was recommended he slowly return to activity through modified workouts, he felt he could fully participate as he remained pain free. He reported for follow up visits as scheduled, was truthful about his activity level and was responsive to completing the patient-based outcome forms.

\section{DISCUSSION}

Anterior knee pain is a common complaint with many causative factors including acute injury, congenital malalignment, poor motor control of the hip, pelvis, knee and core, as well as poor foot posture. ${ }^{1-7}$ Poor motor control of the hip, knee and pelvis may result in an internally rotated femur, with an accompanying externally rotated tibia, creating joint dysfunction. ${ }^{2-5,14,15}$

Utilization of the MC MWM in this specific case study produced positive results which are consistent with results found in a review of the tenets and prescription of MWM by Hing, Bigelow and Bremner in the November, 2008 New Zealand Journal of Physiotherapy. ${ }^{13}$ The common significant results were reduced pain levels, increased strength and functional improvements when compared to placebo. ${ }^{13}$ The application of an internal rotation force on the tibia as the patient moved the knee through flexion and extension resulted in decreased pain and a change of faulty joint arthrokinematics. The MC TIR MWM is a gentle, pain-free intervention strategy for addressing symptoms associated with

Clinical Practice in Athletic Training Volume 2 - Issue 3 - November 2019 
AKP.11-15,17 Proper application of a subtherapeutic dose within the initial assessment indicated the MWM could be clinically effective due to the production of the PILL effect. ${ }^{15}$ The tape application is believed to prolong the mobilization effect by providing a constant stimulus on the joint proprioceptors. ${ }^{12-15}$

The clinician must be well-versed in the contraindications for joint mobilization before applying any mobilizing force on a joint surface, with a complete understanding of arthrokinematics and skills to sense changes in joint mobility. Application of a MWM allows the patient to provide feedback to the clinician throughout the treatment. If the patient reports pain, the clinician should pause at the starting point, reposition the hands, making sure hand placement, direction, and pressure is comfortable to the patient, however, if the patient reported pain persists, the MWM would be discontinued. Following the MC guidelines, a MWM treatment intervention should be pain-free and the reduction of pain should be immediate. 11-19,22

Utilization of patient-reported outcome measures can provide the clinician with information regarding the patient's pain and function, along with the identification of the patient's quality of life that may be overlooked if not specifically assessed throughout the patient care process. Making a concerted effort to appreciate how the injury is impacting the patient's daily life outside their sport (e.g., transportation, food preparation, attending classes, personal relationships, completing school work) provides the clinician with a higher level of understanding of the patient's overall well-being. Pain and disability scales provided information regarding improvements that were important to the patient (pain-free basketball, climbing stairs to apartment), as well as to the clinician (decreased pain and increased range of motion). ${ }^{23-27}$ Identifying and testing a CSIM prior to and after an intervention is effective in determining if important changes have taken place that are relevant to both the clinician and

Copyright (C) by Indiana State University All rights reserved. ISSN Online 2577-8188 the patient. ${ }^{15}$ Continued monitoring of pain and dysfunction through patient-reported outcome measures is important to determine the immediate and lasting effect of the MWM intervention. While the outcome measures were collected for only two weeks until the patient was released to full activity, he was monitored daily for any return of pain or dysfunction. Prolonged outcome collection would have produced a more viable conclusion to the efficacy of the TIR MWM technique.

\section{CLINICAL BOTTOM LINE}

This case study was produced in an effort to highlight a successful intervention for one patient reporting AKP. The MC MWM is a treatment intervention guided by easy to follow acronyms for the desired outcome (PILL) and the technique of each intervention (CROCKS). The technique allows the patient and clinician to communicate throughout the mobilization to ensure a pain-free intervention, and the importance of the pain-free aspect of the mobilization cannot be understated. If the PILL effect had not been produced during the sub-therapeutic dose, the MWM would not have been clinically indicated.11-17 The tape application was used to prolong the mobilization and provide continued neurophysiological input to aid in the success of the intervention.

Careful assessment and clinical reasoning must take place in order to determine the proper intervention for each patient. This patient had symptoms consistent with those of patellar tendinopathy which had not improved with his treatment of ice and rest. He did report positive initial results during the assessment with the subtherapeutic dose of the MC TIR MWM. The improvement in pain scale and muscle testing results are subjective from both the patient and the clinician, and may be a limitation of this case study. A change in joint arthrokinematics is believed to directly affect both pain and strength results of the MC TIR MWM.12-15,17-18,22 Further case studies and controlled trials are needed to 
further investigate clinical efficacy. The incorporation of the MC MWM into an athletic training practice can be a powerful treatment paradigm that may produce positive results.

\section{REFERENCES}

1. Coppack R, Etherington J, Will A. The effects of exercise for the prevention of overuse anterior knee pain. Am J Sports Med. $2011 ; 39 .(5): 940-948$. https://doi.org/10.1177/0363546510393 $\underline{269}$

2. Nguyen A, Schultz $S$, Schnidtz $R$, Luecht $R$, Perrin D. A preliminary multifactorial approach describing the relationships among lower extremity alignment, hip muscle activation \& lower extremity joint excursion. $J$ Athl Train. $2011 ; 46(3): 246-256$. https://doi.org/10.4085/1062-605046.3.246.

3. Powers C, Landel R, Perry J. Timing and intensity of vastus muscle activity during functional activities in subjects with ad without patellofemoral pain. Phys Ther. 1996;76(9):946-955. https://doi.org/10.1093/pti/76.9.946

4. McConnell J. Management of a difficult knee problem. Man Ther. 2013;18:258-263. https://doi.org/10.1016/i.math.2012.05.01 8

5. Bolga L, Malone T, Umberger B, Uhl T. Hip strength and hip and knee kinematics during stair descent in females with and without PFPS. J Orthop Sports Phys Ther. 2008;38(1):1 2-18. https://doi.org/10.2519/iospt.2008.2462

6. Willy R, Scholz J, Davis I. Mirror gait retraining for the treatment of patellofemoral pain in female runners. Clin Biomech. 2012;27:1045-1051. https://doi.org/10.1016/i.clinbiomech.2012 .07 .011

7. Willy RW, Davis IS. The effect of a hipstrengthening program on mechanics during running and during a single-leg squat. I Orthop Sports Phys Ther. $2011 ; 41: 625-632$. https://doi.org/10.2519/iospt.2011.3470.

8. Kaltenborn, F. The Spine: Basic evaluation and mobilization techniques.2nd Edition. 1993. Banta ISG, Minneapolis MN.

Copyright (C) by Indiana State University All rights reserved. ISSN Online 2577-8188
9. Klafs, C and Arnheim, D. Modern Principles of Athletic Training. 2 $2^{\text {nd }}$ Edition. 1969. C.V. Mosby Company. St. Louis MO.

10. Kaminski T, Hertel J, Amendola N, Docherty C, Dolan M, Hopkins J, Nussbaum E, Poppy W, Richie D. National Athletic Trainer's Association position statement: Conservative management and prevention of ankle sprains in athletes. J Athl Train. 2013;48(4):528-545. https://doi.org/10.4085/1062-605048.4.02

11. Professional Education Council of the National Athletic Trainer's Association. 2011. Athletic Training Competencies. $5^{\text {th }}$ Edition.

12. Mulligan, BR. Manual Therapy, NAGS, SNAGS, MWMS etc. $6^{\text {th }}$ Edition. Orthopedic Physical Therapy Products

13. Hing W, Bigelow R, Bremner T. Mulligan's mobilization with movement: $A$ review of the tenets and prescription of MWM. N Z J Physiother. $\quad 2008 ; 36(3): 144-164$. https://doi.org/10.1179/imt.2009.17.2.39E

14. Vincenzino, B Hing, W Rivett, D Hall, T. (2011). Mobilization with Movement: The Art and Science. Elsevier, Sydney.

15. Hing, W Hall, T Rivett, D Vicenzino, B Mulligan, B. (2015).The Mulligan Concept of Manual Therapy: textbook of techniques. Elsevier. Australia.

16. Baker R, Nasypany A, Seegmiller J, Baker J. The mulligan concept: Mobilizations with movement. International Journal of Athletic Training and Therapy. 2013;18(1):30-34. https://doi.org/10.1123/ijatt.18.1.30.

17. Vicenzino B, Paungmali A, Teys P. Mulligan's mobilization with movement, positional faults and pain relief: Current concepts from a critical review of literature. Man Ther. 2007; 1 2:98-1 28. https://doi.org/10.1016/i.math.2006.07.01 2

18. Mulligan Concept Founder's Profile. www.bmulligan.com. Official International website.

19. Collins N, Teys P, Vicenzino B. The initial effects of a mulligan's mobilization with movement technique on dorsiflexion and pain in sub-acute ankle sprains. Man Ther. 2004;9(2):77-92.

https://doi.org/10.1016/S1356689x(03)00101-2
56 
20. Hubbard TJ, Hertel J. Anterior positional fault of the fibula after sub-acute lateral ankle sprains. Man Ther. 2008;13(1):63-67. https://doi.org/10.1016/i.math.2006.09.00 $\underline{8}$

21. Hsieh CY, Vicenzino B, Yang $\mathrm{CH}$, Hu MH, Yang C. Mulligan's mobilization with movement for the thumb: A single case report using magnetic resonance imaging to evaluate the positional fault hypothesis. Man Ther. (2002);7(1):4449.

https://doi.org/10.1054/math.2001.0434

22. Takasaki $H$, Hall $T$, Jull $G$. Immediate and short-term effects of mulligan mobilization with movement on knee pain and disability associated with knee osteoarthritis: A prospective case series. Physiother Theory Pract. 2013;29(2):87-95. https://doi.org/10.3109/09593985.2012. 702854

23. Vela L, Haladay D, Denegar C. Transient disablement in the physically active with musculoskeletal injuries, part I: A descriptive model. J Athl Train. 2010;45(6):615-629. https://doi.org/10.4085/1062-605045.6 .615

24. Vela I, Denegar C. The disability in the physically active scale, part II: The psychometric properties of an outcomes scale for musculoskeletal injuries. I Athl Train. 2010;45(6):630-641.

25. Ferreira-Valente $M$, Pais-Ribeiro J, Jenson $M$. Validity of four pain intensity rating scales. Pain. $\quad 2011$;(152):2399-2404. https://doi.org/10.1016/i.pain.2011.07.00 $\underline{5}$

26. Chatman A, Hyams S, Neel J, Binkley J, Stratford P, Schomberg A, Stabler M. The patient-specific functional scale: Measurement properties in patients with knee dysfunction. Phys Ther. 1997;77:820-829. https://doi.org/10.1093/pti/77.8.820

27. Farrar J, Portenoy R, Berlin J, Kinman J, Strom B. Defining the clinically important difference in pain outcome measures. Pain. 2000;(88): 287-294. https://doi.org/10.1016/s03043959(00)00339-0 